\title{
Diversidad de esporas de micorrizas arbusculares modificada por ciertas prácticas agronómicas del cultivo de trigo
}

Gamarnik, Marilée (1) $^{\text {Z Zambrano Soledispa, Ana }}{ }^{(1)}$; Di Salvo, Luciana P. ${ }^{(2)(1)^{*}}$; García de Salamone, Inés E. ${ }^{(1)}$

${ }^{(1)}$ Universidad de Buenos Aires, Facultad de Agronomía, Departamento de Biología Aplicada y Alimentos, Cátedra de Microbiología Agrícola

${ }^{(2)}$ Consejo Nacional de Investigaciones Científicas y Tecnológicas

*E-mail: disalvol@agro.uba.ar

Introducción: El cultivo de trigo (Triticum aestivum) es uno de los principales cultivos de la región pampeana. Para asegurar una buena producción, es fundamental la implementación de buenas prácticas agrícolas, de manera de asegurar la sostenibilidad del ambiente. Una de las formas es mediante la inoculación con microorganismos benéficos del suelo, como la rizobacteria promotora del crecimiento vegetal Azospirillum brasilense. Ésta permite aumentar la producción de los cultivos en forma sostenible a través de diversos mecanismos de interacción planta-bacteria.Junto con otro tipo de microorganismo benéfico presente en los suelos,los hongos formadores de micorrizas arbusculares, aportan diversos beneficios para las plantas, como una mejora en la eficiencia del uso de los nutrientes del suelo. Así, la práctica de inoculación podría generar una reducción en los problemas ambientales producto de la fertilización de los cultivos. Sin embargo, es necesario conocer el efecto de ambas prácticas agrícolas sobre las comunidades microbianas nativas, en orden de determinar la sustentabilidad de las mismas.

Materiales y métodos: Se evaluaron los efectos de la fertilización nitrogenada y fosforada y la inoculación con cepas de A. brasilense sobre la diversidad de esporas de hongos micorrícicos arbusculares. Se realizó un ensayo de trigo a campo con diseño en parcelas divididas y arreglo factorial con tres factores: i) fertilización nitrogenada, en tres niveles de aplicación de urea $\left(0,75\right.$ y $\left.150 \mathrm{~kg} \mathrm{ha}^{-1}\right)$, ii) fertilización fosforada, en tres niveles de aplicación de superfosfato triple $\left(0,60\right.$ y $\left.120 \mathrm{~kg} \mathrm{ha}^{-1}\right)$ y iii) factor inoculación, en dos niveles: un tratamiento control sin aplicación de inoculante y un tratamiento con la inoculación formulada a partir de dos cepas de A. brasilense (40M y 42M). Se tomaron muestras de suelo en dos estadios del cultivo, macollaje y llenado de grano. A partir de las muestras de suelo se realizó la extracción de esporas mediante una técnica de tamizado húmedo. Éstas se cuantificaron y clasificaron según morfotipos por observación al microscopio con aumento de 40x y 100x. Con los datos de abundancia se calculó el índice de diversidad de Shannon. La información obtenida se sometió a análisis de medias y multivariado, utilizando el software Infostat 2011.

Resultados: En ambos estadios del cultivo se observaron ocho morfotipos diferentes de esporas de hongos micorrícicos arbusculares nativos, con distinta abundancia de cada uno de ellos. Además, la fertilización nitrogenada y la inoculación con A. brasilense no modificaron la diversidad de esporas de estos hongos presentes en el suelo rizosférico. Por el contrario, la aplicación de $60 \mathrm{~kg} \mathrm{ha}^{-1}$ de superfosfato triple generó un aumento de la diversidad de esporas de estos hongos en ambos estados ontogénicos del cultivo de trigo.

Conclusiones: En este trabajo se muestra que ciertas prácticas agronómicas, como la fertilización fosforada, pueden modificar la diversidad de hongos micorrícicos arbusculares nativos, mientras que otras, como la inoculación con A. brasilense y la fertilización nitrogenada, no producen modificaciones. Estos resultados contribuyen a determinar la sustentabilidad de estas prácticas agronómicas.

Agradecimientos: Este trabajo fue parcialmente financiado por el proyecto FONCYT 2008 PICT 1864 del MinCyT y el proyecto UBACyT 20020090100255 de la UBA. Agradecemos al personal de "El Correntino", 30 de Agosto, provincia de Buenos Aires. 